\title{
Simulation of resin-impregnation, heat-transfer and cure in a resin-injection pultrusion process
}

Sandberg, Michael; Rasmussen, Filip S.; Hattel, Jesper H.; Spangenberg, Jon

Published in:

AIP Conference Proceedings

Link to article, DOI:

$10.1063 / 1.5112527$

Publication date:

2019

Document Version

Publisher's PDF, also known as Version of record

Link back to DTU Orbit

Citation (APA):

Sandberg, M., Rasmussen, F. S., Hattel, J. H., \& Spangenberg, J. (2019). Simulation of resin-impregnation, heat-transfer and cure in a resin-injection pultrusion process. AlP Conference Proceedings, 2113(1), [020022]. https://doi.org/10.1063/1.5112527

\section{General rights}

Copyright and moral rights for the publications made accessible in the public portal are retained by the authors and/or other copyright owners and it is a condition of accessing publications that users recognise and abide by the legal requirements associated with these rights.

- Users may download and print one copy of any publication from the public portal for the purpose of private study or research.

- You may not further distribute the material or use it for any profit-making activity or commercial gain

- You may freely distribute the URL identifying the publication in the public portal 


\section{Simulation of resin-impregnation, heat- transfer and cure in a resin-injection pultrusion process}

Cite as: AIP Conference Proceedings 2113, 020022 (2019); https://doi.org/10.1063/1.5112527

Published Online: 02 July 2019

Michael Sandberg, Filip S. Rasmussen, Jesper H. Hattel, and Jon Spangenberg
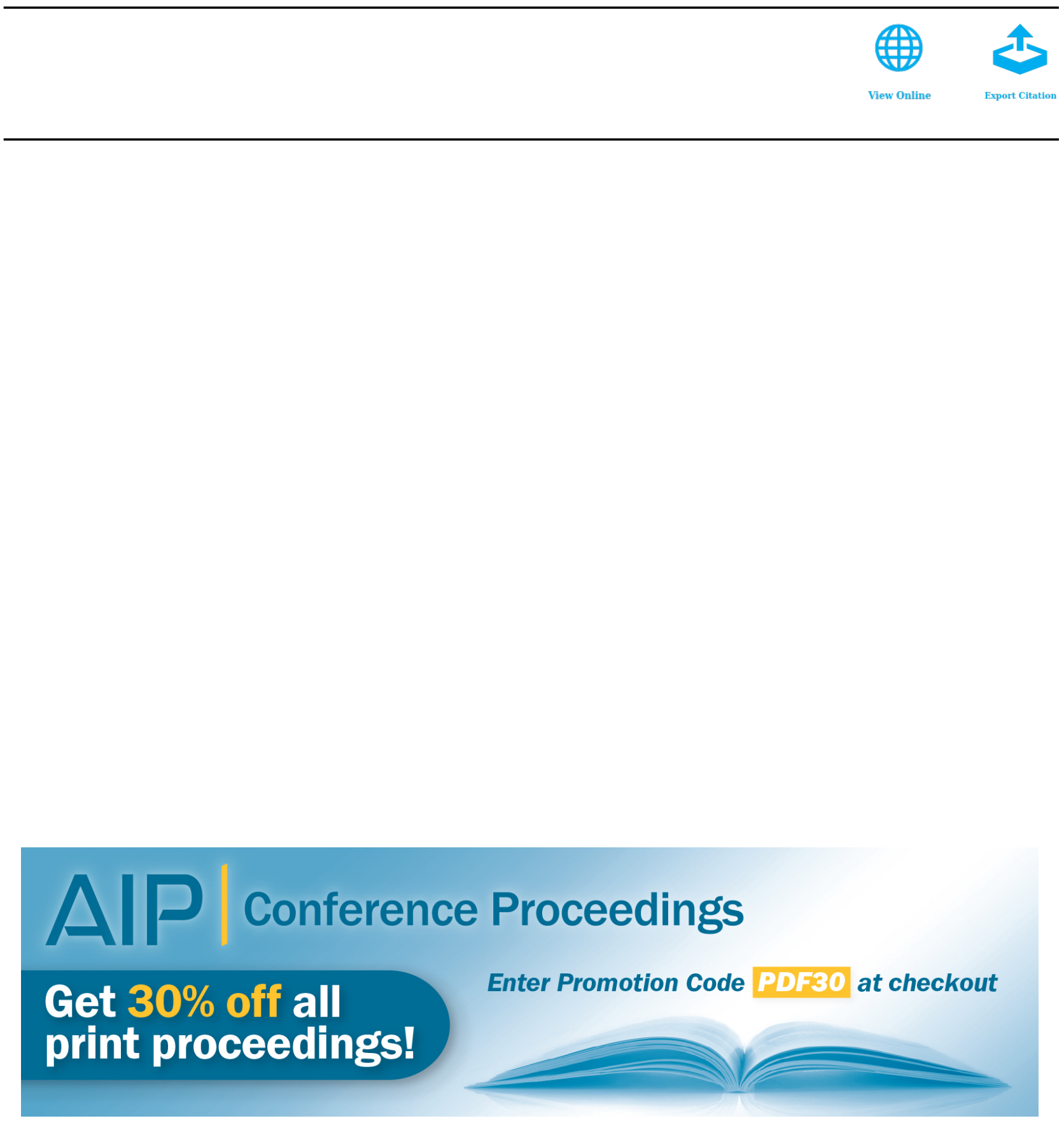


\title{
Simulation of resin-impregnation, heat-transfer and cure in a resin-injection pultrusion process
}

\author{
Michael Sandberg ${ }^{1, a)}$, Filip S. Rasmussen ${ }^{1}$, Jesper H. Hattel ${ }^{1}$ and Jon Spangenberg ${ }^{1}$ \\ ${ }^{1}$ Produktionstorvet Building 425, DK-2800 Kgs. Lyngby, Department of Mechanical Engineering, Technical \\ University of Denmark

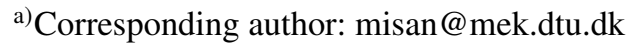

\begin{abstract}
In this paper has a numerical framework for multiphysical simulation of resin-impregnation, heat-transfer and cure in a resin-injection pultrusion process been developed. Using the framework, the material flow through the pultrusion die was studied for the manufacture of a $100 \mathrm{~mm}$ thick glass fibre reinforced polyurethane (thermoset) composite profile. The results demonstrated that while curing is initiated near the heated die-walls, a yet stronger reaction is simultaneously obtained at the centre of the profile. The results were qualitatively compared to measurements from an industrial pultrusion line, which confirmed the trends of the material flow.
\end{abstract}

\section{INTRODUCTION}

Resin-injection pultrusion (RIP) is a high-quality, cost-effective and continuous process for the manufacture of composite profiles with a constant cross-section. In RIP, the dry fibre material is pulled through a die, where the fibre material is impregnated with a resin by means of pressure-driven resin-injection. Subsequently, the composite profile is heated, which initiates and accelerates the exothermic curing reaction. Finally, the cured composite profile leaves the die and is cut into desired lengths.

Resin-injection pultrusion is a closed mould process, whereby it is difficult to measure or observe the different sub-steps of the material flow through the die. As a result, the sensitivities and implications of the different process parameters are often unknown and the process not necessarily well understood. For this reason is computer simulation an important tool in the design and optimisation of existing and new RIP processes.

Computer simulation of the RIP process has over the years gained significant interest in academic research, and several research papers on resin-impregnation, heat-transfer and cure can be found in the literature. For example, Palikhel, Roux, and Jeswani [1] studied how the pressure build-up and fibre wet-out in a tapered impregnation chamber is correlated to the profile-advancing pulling speed and wedge angle. From the same research group, the effect of the number of inlet slots and their location was studied in [2], and the influence of fibre compaction was discussed in [3]. The heat-transfer and curing kinetics incl. process-induced stresses and shape distortions have been studied extensively by Baran et al. in e.g. [4, 5]. Multiphysical simulations, considering both the resin-impregnation, heattransfer and curing kinetics can also be found in the literature $[6,7,8]$. Common for this work, however, is that the impregnation step is to some degree considered separate to the heating die, whereby a de-coupling of the interaction of resin impregnation, heat-transfer and curing kinetics is inherently assumed.

In the present study, a multiphysical simulation of a RIP process is presented. The model fully couples resinimpregnation, heat-transfer and resin cure, which has not been done before. The numerical framework is based on the finite volume method (FVM), with a level-set method to trace the location of the resin flow front. The simulations are conducted for a realistic industry case and results are qualitatively compared to measurements from an industrial pultrusion line.

\footnotetext{
Proceedings of the 22nd International ESAFORM Conference on Material Forming AIP Conf. Proc. 2113, 020022-1-020022-6; https://doi.org/10.1063/1.5112527 Published by AIP Publishing. 978-0-7354-1847-9/\$30.00
} 


\section{METHOD}

In this section, the governing equations for the material flow through the die in a pultrusion line are described.

\section{Resin flow}

For a Newtonian fluid (the resin), the flow through a porous media (fibre material) moving with a bulk velocity of $u_{i, f}$ is governed by Darcy's law:

$$
u_{i}=u_{i, f}+\frac{K_{i j}}{\mu \theta_{v}} \frac{\partial p}{\partial x_{j}}, \quad q_{i}=\theta_{v} u_{i}
$$

where, in this context, the bulk velocity of the fibres, $u_{i, f}$, corresponds to the profile-advancing pulling speed of the profile. Darcy's law relates the spatial velocities, $u_{i}$, in the $i$-direction to the pressure gradient, $\partial p / \partial x_{i}$, and the material parameters $K_{i j}, \theta_{v}$ and $\mu$. These coefficients are the permeability tensor and porosity of the fibre material, and the dynamic viscosity of the resin, respectively. Off-diagonal terms in $K_{i j}$ are assumed to be zero. Finally, $q_{i}$ is the volumetric discharge that is often referred to as the superficial velocity. Please note that repeated indices in tensor equations (indices $i$ and $j$ ) implies summation.

To set up an equation for the pressure, mass conversation is enforced to Eq. 1, which means that the divergence of the volumetric discharge must be in balance with any sources or sinks, $s$ :

$$
\frac{\partial}{\partial x_{i}}\left(\frac{K_{i j}}{\mu} \frac{\partial p}{\partial x_{j}}\right)=s
$$

Eq. (2) is valid when $u_{i, f}$ is constant in all directions.

While some flow models consider a partially saturated zone near the flow front as part of the impregnation mechanisms, Darcy's law formulated as Eqs. (1-2) implies that there exists a sharp transition between the resin (the saturated zone) and the dry fibre-material (the unsaturated zone) during the impregnation step. For layups consisting of fabrics (e.g. non-crimp or woven), pore space introduces a partially saturated zone near the flow front as the resin travels faster between rovings under pressure-induced flow. Such cases are not captured by Eqs. (1-2) and the transient, progressive impregnation mechanisms must instead be considered through an appropriate non-saturated flow law when applicable $[9,10,11]$. In RIP, single rovings are often used instead of fabrics, as it has some cost and structural benefits. Single rovings are cheaper, as the fibre material does not need to be processed into a fabric, and they allow for a higher volume fraction, as unbounded fibre-material can be more densely packed. When the pore space between rovings is limited, the partially saturated zone near the flow front will be short, which justifies the flow model in Eqs. (1-2) for layups consisting of single rovings in RIP.

\section{Flow front tracker}

The flow front is tracked by the level-set method that was initially introduced by Sussman, Smereka, and Osher [12]. In this approach, a level set function, $\phi$, holds the absolute distance to the interface (the resin flow front) in the form of a signed distance function. This means that the flow front location is identified by the zero-isocontour of the level set function, $(\phi=0)$, and the domain is split by the sign of $\phi$, where the resin occupies $\phi<0$ and the dry fibres $\phi>0$.

As the resin infiltrates the fibre material, the level-set function is advected in the velocity field from Eq. 1:

$$
\frac{\partial \phi}{\partial t}+u_{i} \frac{\partial \phi}{\partial x_{i}}=0
$$

As the level-set function is advected in the velocity field, $\phi$ generally loses its property of being a signed distance function. To maintain this property, $\phi$ has to be regularly reconstructed, which is usually referred to as reinitialisation. In this paper, the single-step reinitialisation scheme by $\mathrm{Fu}, \mathrm{Hu}$, and Adams [13] is applied after every time step.

\section{Heat-transfer and cure}

The energy balance incl. the exothermic heat generation from the curing reaction reads:

$$
\rho C \frac{\partial T}{\partial t}+\left(u_{i, m} \theta_{v} \rho_{m} C_{m}+u_{i, f}\left(1-\theta_{v}\right) \rho_{f} C_{f}\right) \frac{\partial T}{\partial x_{i}}-\frac{\partial}{\partial x_{i}}\left(\lambda_{i j} \frac{\partial T}{\partial x_{j}}\right)=r
$$


which is a conventional energy conservation equation for transient convection-diffusion with internal heat generation. Eq. (4) accounts for the temporal change in energy due to convection from bulk transport of the resin, $u_{i, m}$, the convection due to the pulling speed of the fibre, $u_{i, f}$, and diffusion through heat conduction. The heat generated from the exothermic curing reaction enters through the source term, $r$. The material properties are the density, $\rho$, the specific heat, $C$, and the heat conductivity tensor $\lambda_{i j}$. Off-diagonal terms in $\lambda_{i j}$ are assumed to be zero. Terms with no subscripts denote the composite, i.e. lumped values for the resin, $m$, fibres, $f$, or the die.

The heat generated from the exothermic curing reaction enters the source term as:

$$
r=\theta_{v} \rho_{m} H_{t} R_{r}
$$

where $H_{t}$ is the total heat generated during the chemical reaction, and $R_{r}=R_{r}(\alpha, T)$ is the cure degree rate, given as an Arrhenius equation [14]:

$$
R_{r}=A_{0} \exp \left(\frac{E_{a}}{R T}\right)(1-\alpha)^{n}
$$

where $\alpha$ is the degree of cure, $A_{0}$ is the pre-exponential constant, $n$ is the kinetic exponent, $E_{a}$ is the activation energy, and $R$ is the universal gas constant. The degree of cure is subjected to advection by the velocity of the resin:

$$
\frac{\partial \alpha}{\partial t}+u_{i, m} \frac{\partial \alpha}{\partial x_{i}}=R_{r}
$$

\section{Numerical framework}

Eqs. (1-4) are discretised using FVM and solved in the technical programming language, MATLAB ${ }^{\mathrm{TM}}$. The solution method consists of two successive steps. The first step is to solve the pressure equation, Eq. (2), implicitly. Secondly, velocities near the interface can be determined and the interface is locally advected using an explicit forward Euler step for Eq. (3). The temperature and the degree of cure can subsequently be determined in the new configuration using an implicit backward Euler step based on Eqs. (4) and (7), respectively.

\section{CASE STUDY}

The case study concerns pultrusion of a $100 \mathrm{~mm}$ thick profile, consisting of a polyurethane (PUR) thermoset resin reinforced with rovings of glass fibres. The case study is illustrated in Fig. 1 and all material properties are listed in Table 1 . The case is considered in $2 \mathrm{D}$ on a $200 \times 40$ equidistant grid, with symmetry exploited at the centreline.

The die is $1.5 \mathrm{~m}$ long, which is a typical length of a long pultrusion die [15], and it has a wall thickness of 50 $\mathrm{mm}$. The resin is injected at the top and bottom of the die at an injection pressure of $30 \mathrm{bar}$ and a temperature of $25^{\circ} \mathrm{C}$. The resin enters the profile through a $50 \mathrm{~mm}$ wide manifold located $200 \mathrm{~mm}$ from the entrance to the die. At the top and bottom of the die, the first $300 \mathrm{~mm}$ of the die is cooled to a constant temperature of $35^{\circ} \mathrm{C}$, while the last $900 \mathrm{~mm}$ of the die is heated to 110,190 , and $170^{\circ} \mathrm{C}$ over three equidistant steps. The remaining of the die is cooled by means of natural convection to the ambient surroundings with a temperature of $t_{\infty}=25^{\circ} \mathrm{C}$. The fibre material is preheated to

\begin{tabular}{|c|c|c|c|c|c|}
\hline Physics/Component & & & & & Ref. \\
\hline Flow* & $K_{11}\left[\mathrm{~m}^{2}\right]$ & $K_{22}\left[\mathrm{~m}^{2}\right]$ & $\mu[\mathrm{Pa} \mathrm{s}]$ & $\theta_{v}[\mathrm{~Pa} \mathrm{~s}]$ & \\
\hline Fibres/resin & $8.98 \cdot 10^{-12}$ & $1.90 \cdot 10^{-12}$ & 0.2 & 0.45 & {$[16,17]$} \\
\hline Heat-transfer & $\lambda_{11}[\mathrm{~W} /(\mathrm{m} \mathrm{K})]$ & $\lambda_{22}[\mathrm{~W} /(\mathrm{m} \mathrm{K})]$ & $C[\mathrm{~J} /(\operatorname{kg~K})]$ & $\rho\left[\mathrm{kg} / \mathrm{m}^{3}\right]$ & \\
\hline Fibres & 11.4 & 1.04 & 670 & 2560 & $\mathrm{IH}^{\dagger}$ \\
\hline Resin & 0.3 & 0.3 & 1500 & 1200 & and \\
\hline Die & 40 & 40 & 460 & 7833 & [18] \\
\hline Cure-kinetics & $A_{0}[1 / \mathrm{s}]$ & $E_{a}[\mathrm{~J} / \mathrm{mol}]$ & $n[-]$ & $H_{t}[\mathrm{~J} / \mathrm{kg}]$ & \\
\hline Resin & $1.9 \cdot 10^{4}$ & $43.5 \cdot 10^{3}$ & 1.56 & $360 \cdot 10^{3}$ & [19] \\
\hline
\end{tabular}
a temperature of $50^{\circ} \mathrm{C}$ before entering the die to shorten the cure time [15]. The pulling speed is set to $0.2 \mathrm{~m} / \mathrm{min}$.

TABLE 1. Material parameters and references for case study.

* Estimated based on hexagonal stacking and a fibre radius of $R=17 / 2 \mu \mathrm{m}$.

$\dagger$ In-house data 


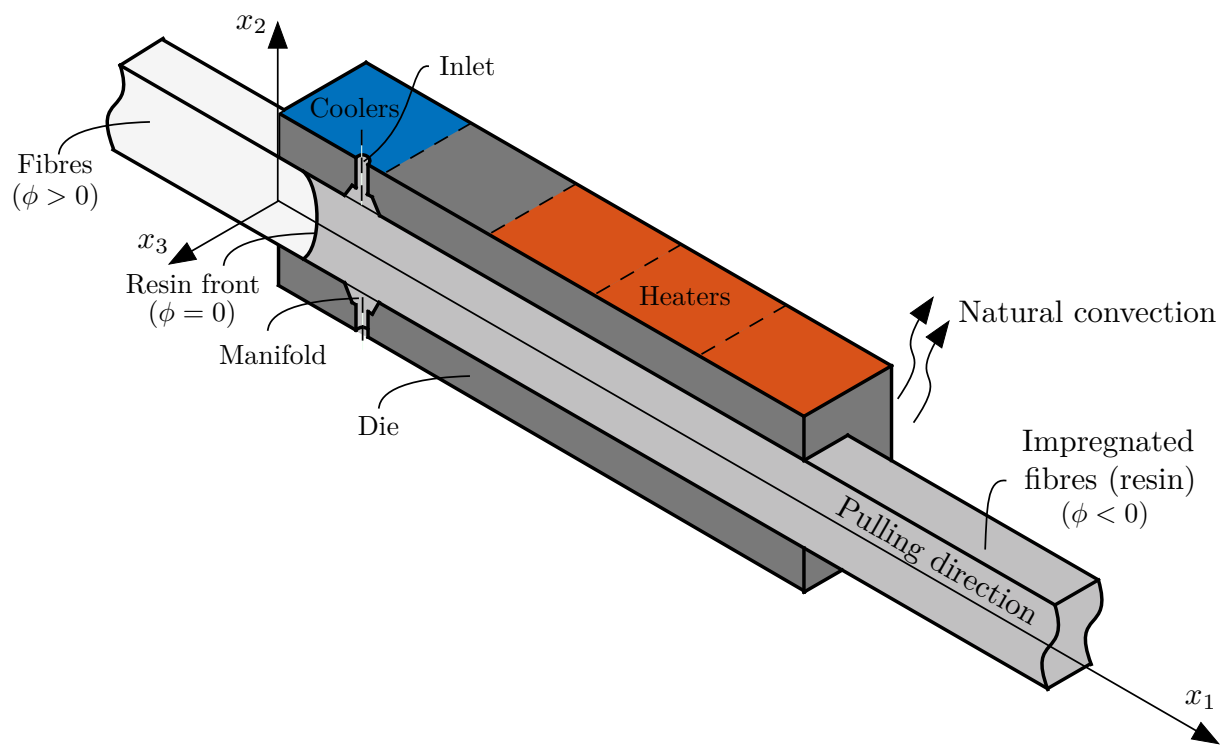

FIGURE 1. Cut-through view ( $x_{1}, x_{2}$-plane) of the case study (not to scale) of a thick composite profile. The level set function, $\phi$, indicates how the domain is split by the resin front at $\phi=0$ into the dry fibre material, $\phi>0$, and the impregnated fibres (resin), $\phi<0$.

\section{Results and discussion}

The stationary solutions for temperature, pressure and degree of cure can be seen in Figs. 2(a-c). The temperature near the edge and at the centre of the profile are plotted in Fig. 3(a). Temperature measurements from an industrial pultrusion line, with similar, but different, dimensions, materials, and process conditions, are plotted in Fig. 3(b).

\section{Resin flow}

As it can be seen in Fig. 2(a), the full cross-section achieves complete wet-out under the subjected process conditions. A pressure build-up of approximately $25 \%$ of the inlet pressure is maintained at the exit of the chamber. The flow front appears concave, with a back-flow of approximately $5 \mathrm{~cm}$ behind the inlet at the die-wall. The flow front starts at the centre of the profile approximately $5 \mathrm{~cm}$ after the inlet.

From the temperature measurement in Fig. 3(b), the flow front location can be estimated based on the point where the temperature suddenly changes. The flow front location is indicated as points $\mathrm{A}$ and $\mathrm{C}$, while the inlet is at point $\mathrm{B}$ which is known from the geometry of the die. The location of the inlet can also be identified as the point where a sharp drop in temperature is observed, as the thermocouple reaches the unheated resin inlet flow. Based on points A and $\mathrm{C}$ in Fig. 3(b), the flow front also appears concave.

\section{Temperature rise and resin cure}

Based on Fig. 3(a), the temperature at the edge of the profile drops from the entrance of the die towards the resin inlet. Under the resin inlet, the temperature drops sharply as the bulk transport of resin with low inlet temperature is strong in this region. Further into the die, the resin cures from the die-walls into the profile (cf. Fig. 2b-c). A local peak in temperature coming from the exothermic curing reaction is observed approximately $75 \%$ into the die, where the resin near the die-wall is more than $90 \%$ cured (c.f. Fig. 2c).

At the centre of the profile, the temperature appears almost constant at $50^{\circ} \mathrm{C}$, which corresponds to the preheated temperature of the fibres. As the fibres reach the resin, the temperature starts to rise and approximately $50 \%$ into the die, the resin is more than $90 \%$ cured (c.f. Fig. 2c). This behaviour indicates that a faster exothermic curing reaction starts from the centre of the profile in addition to the reaction that starts near the die-walls.

The same tendencies in the development of the temperatures are observed in the measurements from the industrial pultrusion line (c.f. Fig. 3b) with some minor differences. For example, i) at the entrance of the chamber in the 


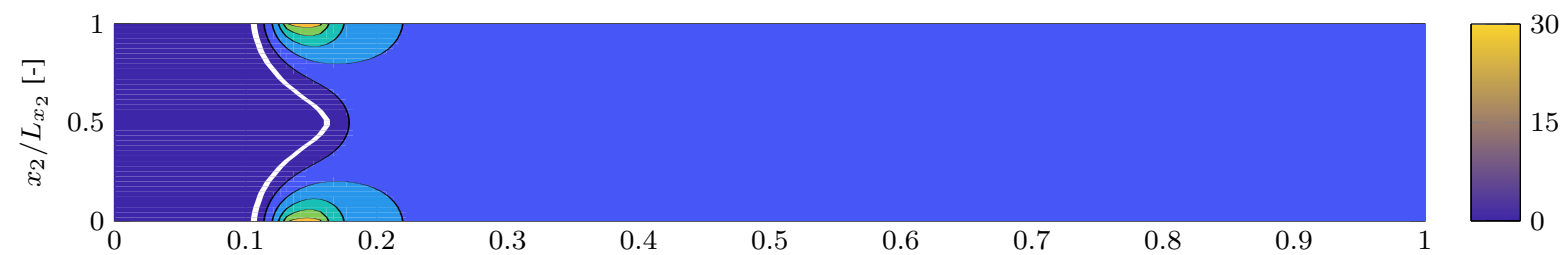

(b) Temperature
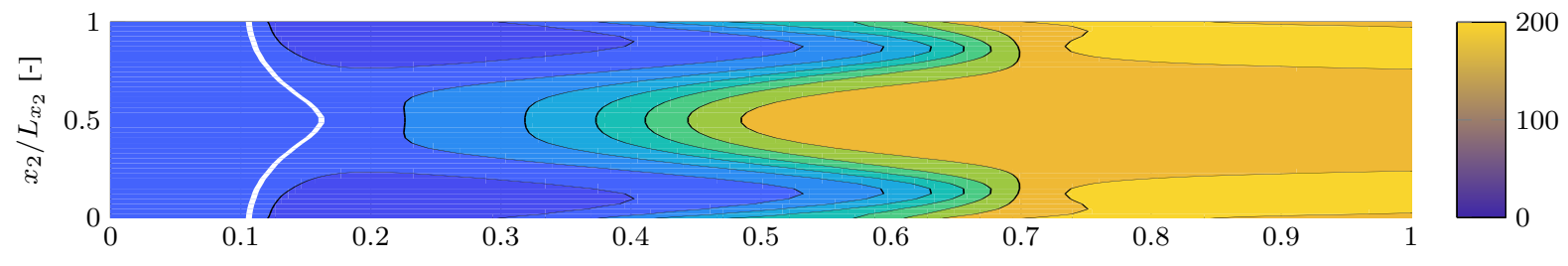

(c) Degree of cure

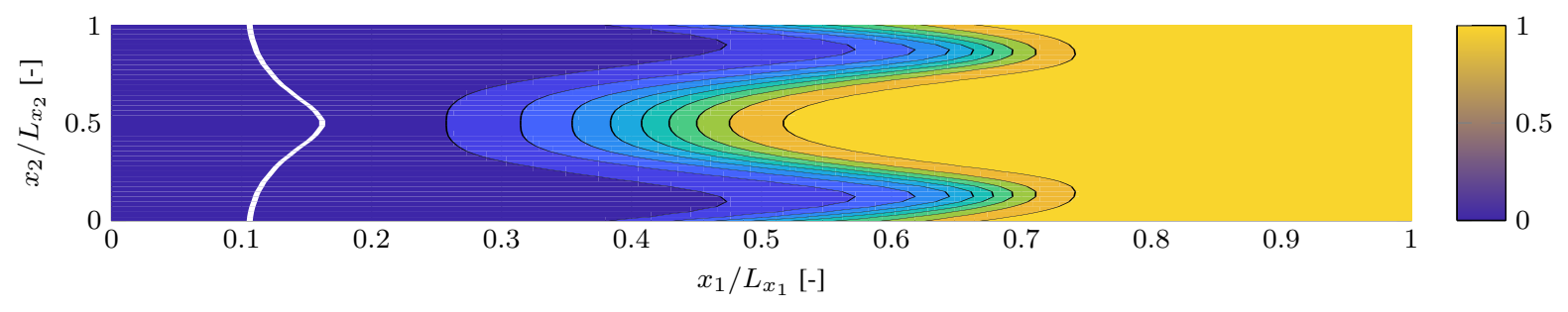

FIGURE 2. (a) Pressure, (b) temperature, and (c) degree-of-cure at steady state. The white line indicate the position of the resin flow front.

industrial pultrusion line, the temperature is lower at the edges compared to the centre of the profile. This could indicate that the fibres are to some degree cooled by the ambient surroundings between the preheater and pultrusion die. ii) The development in temperature through the die appears to be more smooth for the industrial pultrusion line, compared to the simulation results. This could be caused by differences in the design and location of heaters, as well as imperfect thermal contact between the die and the profile.

\section{Transition from liquid to gel to solid}

Established research (e.g. [15]) often illustrates a concave transition from liquid to gel, and from gel to solid, similar to the shape of the flow front. As it is evident in Fig. 2(c), for this thick composite profile manufactured with fibre preheating, the resin cures simultaneously from the die-walls and the profile centre, which makes the transition from liquid to gel, and from gel to solid, both convex and concave at the same time.

\section{CONCLUSION}

In this study, a numerical framework based on the finite volume method and the level-set method for multiphysical simulation of the resin-injection pultrusion process was developed. The framework handles the material flow through the die, i.e. the resin impregnation step, incl. treatment of the resin flow front as a free surface, and the coupling to the heat-transfer and curing kinetics of the resin.

Using the numerical framework, a case study of a thick composite profile was conducted. In the case study, it was shown how the temperature field is affected by the preheating of the fibres and the inlet temperature of the resin. Furthermore, it was demonstrated how curing is both initiated near the die-walls, yet a stronger reaction is observed at the centre of the profile due to preheating of the fibres. The results were qualitatively compared to measurements from an industrial pultrusion line, which confirmed the trends of the material flow. 
(a) Simulation

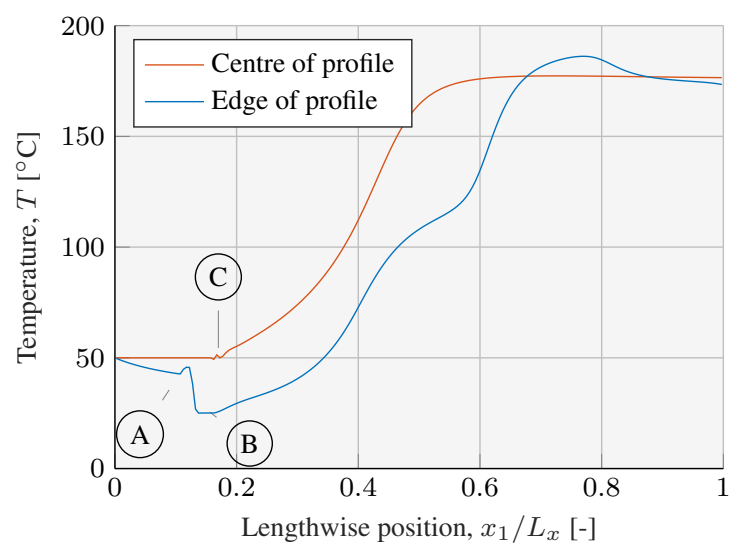

(b) Measured at an industrial pultrusion line

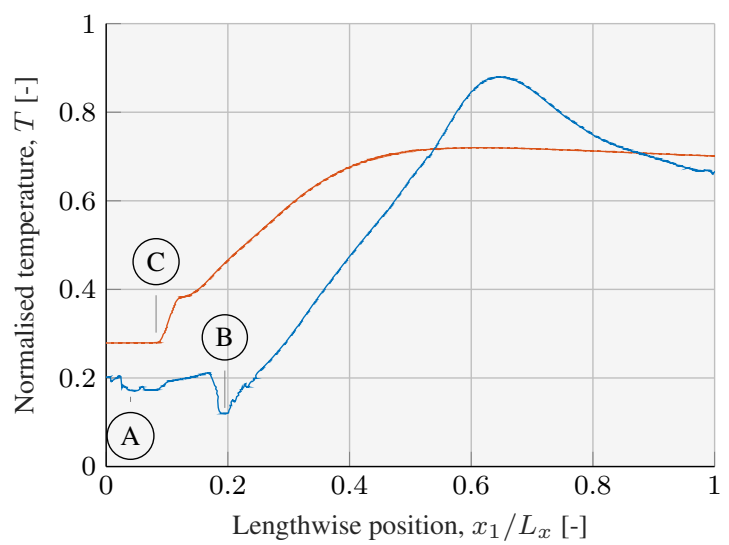

FIGURE 3. The temperature along the length of the profile at the edge and centre of the profile. Simulation results are shown in Fig. (a), while normalised measurements from an industrial pultrusion line with similar, but different, dimensions and materials are shown in Fig. (b). Point A indicates where the thermocouple reaches the resin front in the edge of the profile. At point B, the thermocouple is right below the inlet. Finally, at point $\mathrm{C}$, the thermocouple reaches the resin flow front at the centre of the profile.

In future research, we aim to include the temperature-dependent rheology of the resin. This would e.g. allow for studies on how the resin impregnation step is affected by fibre preheating and resin inlet temperature.

\section{ACKNOWLEDGMENTS}

Martin Larsen (project partner) is greatly acknowledged for discussions and inputs. This work is funded by the Danish Council for Independent Research — Technology and Production Sciences (Grant no. DFF-6111-00112: Modelling the multi-physics in resin injection pultrusion (RIP) of complex industrial profiles).

\section{REFERENCES}

[1] D. R. Palikhel, J. A. Roux, and A. L. Jeswani, Applied Composite Materials 20, 55-72 (2013).

[2] S. Ranjit, J. A. Roux, and A. L. Jeswani, Polymers \& Polymer Composites 22, 495-508 (2014).

[3] N. B. Masuram, J. A. Roux, and A. L. Jeswani, Polymers \& Polymer Composites 25, 419-434 (2017).

[4] I. Baran, C. C. Tutum, M. W. Nielsen, and J. H. Hattel, Composites Part B: Engineering 51, 148-161 (2013).

[5] I. Baran, J. H. Hattel, and C. C. Tutum, Applied Composite Materials 20, 1247-1263 (2013).

[6] R. Gorthala, J. A. Roux, and J. G. Vaughan, Journal of Composite Materials 28, 486-506 (1994).

[7] Z. Ding, S. Li, H. Yang, L. J. Lee, H. Engelen, and P. M. Puckett, Polymer Composites 21, 762-778 (2000).

[8] P. Carlone, F. Rubino, and G. S. Palazzo, AIP Conference Proceedings 1769, p. 60001 (2016).

[9] K. M. Pillai, Journal of Composite Materials 38, 2097-2118 (2004).

[10] V. Michaud, Transport in Porous Media 115, 581-601 (2016).

[11] I. D. Patiño-Arcila and J. D. Vanegas-Jaramillo, Journal of Composite Materials 52, 1915-1946 (2018).

[12] M. Sussman, P. Smereka, and S. Osher, Journal of Computational Physics 114, 146-159 (1994).

[13] L. Fu, X. Y. Hu, and N. A. Adams, Computer Physics Communications 221, 63-80 (2017).

[14] I. Baran, R. Akkerman, and J. H. Hattel, Composites Part B: Engineering 64, 194-201 (2014).

[15] T. Starr, Pultrusion for Engineers (Taylor \& Francis, 2000) p. 303.

[16] B. R. Gebart, Journal of Composite Materials 26, 1100-1133 (1992).

[17] M. Sandberg, J. H. Hattel, and J. Spangenberg, "Numerical modelling and optimisation of fibre wet-out in resin-injection pultrusion processes," in European Conference on Composite Materials (ECCM18 conference proceedings, Athens, Greece, 2018).

[18] I. Baran, R. Akkerman, and J. H. Hattel, Composite Structures 118, 37-48 (2014).

[19] B. Fernandez d'Arlas, L. Rueda, P. M. Stefani, K. de la Caba, I. Mondragon, and A. Eceiza, Thermochimica Acta 459, 94-103 (2007). 